\title{
Between- and within-site variation in medication choices and adverse events during procedural sedation for electrical cardioversion of atrial fibrillation and flutter
}

\author{
David Clinkard, MD, MSc*; Ian Stiell, MD, MSc ${ }^{\dagger \neq}$; Eddy Lang, MD ; Stuart Rose, $\mathrm{MD}^{\S}$; \\ Catherine Clement, $\mathrm{RN}^{\ddagger}$; Robert Brison, $\mathrm{MD}, \mathrm{MPH}^{\pi}$; Brian H. Rowe, MD, MS**; \\ Bjug Borgundvaag, MD, $\mathrm{PhD}^{\dagger+}$; Trevor Langhan, $\mathrm{MD}^{\S}$; Kirk Magee, MD, MSc ${ }^{\ddagger \neq}$; Rob Stenstrom, MD,

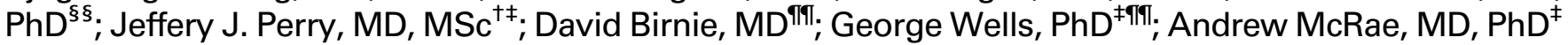

\section{ABSTRACT}

Objectives: Although procedural sedation for cardioversion is a common event in emergency departments (EDs), there is limited evidence surrounding medication choices. We sought to evaluate geographic and temporal variation in sedative choice at multiple Canadian sites, and to estimate the risk of adverse events due to sedative choice.

Methods: This is a secondary analysis of one health records review, the Recent Onset Atrial Fibrillation or Flutter-0 (RAFF-0 [ $n=420,2008]$ ) and one prospective cohort study, the Recent Onset Atrial Fibrillation or Flutter-1 (RAFF-1 [ $n=565$, 2010 - 2012]) at eight and six Canadian EDs, respectively. Sedative choices within and among EDs were quantified, and the risk of adverse events was examined with adjusted and unadjusted comparisons of sedative regimes.

Results: In RAFF-0 and RAFF-1, the combination of propofol and fentanyl was most popular $(63.8 \%$ and $52.7 \%)$ followed by propofol alone $(27.9 \%$ and $37.3 \%)$. There were substantially more adverse events in the RAFF-0 data set $(13.5 \%)$ versus RAFF-1 (3.3\%). In both data sets, the combination of propofol/fentanyl was not associated with increased adverse event risk compared to propofol alone.

Conclusion: There is marked variability in procedural sedation medication choice for a direct current cardioversion in Canadian EDs, with increased use of propofol alone as a sedation agent over time. The risk of adverse events from procedural sedation during cardioversion is low but not insignificant. We did not identify an increased risk of adverse events with the addition of fentanyl as an adjunctive analgesic to propofol.

\section{RÉSUMÉ}

Objectifs: Bien que le recours à la sédation interventionnelle soit chose courante au service des urgences (SU), il existe peu de données sur le choix des médicaments. Aussi avonsnous tenté d'évaluer les différences géographiques et temporelles quant aux choix des sédatifs dans plusieurs centres au Canada, et d'estimer le risque d'événement indésirable lié au choix des sédatifs.

Méthode: Il s'agit d'une analyse secondaire d'un examen de dossiers médicaux, le Recent Onset Atrial Fibrillation or Flutter-0 (RAFF-0 [ $\mathrm{n}=420 ; 2008]$ ), ainsi que d'une étude de cohorte, prospective, la Recent Onset Atrial Fibrillation or Flutter-1 (RAFF-1 [ $\mathrm{n}=565 ;$ 2010-2012]), menés respectivement dans huit et dans six SU, au Canada. Les choix des sédatifs ont été quantifiés entre les SU et dans les SU euxmêmes, et les risques d'événement indésirable, examinés à I'aide de comparaisons rajustées et non rajustées entre différents schémas posologiques de sédatifs.

Résultats: Dans le RAFF-0 et la RAFF-1, I'association de propofol et de fentanyl était le schéma le plus fréquent $(63,8 \%$ et $52,7 \%)$, suivi du propofol seul $(27,9 \%$ et $37,3 \%)$. II y avait sensiblement plus d'événements indésirables relevés dans la base de données du RAFF-0 (13,5\%) que dans celle de la RAFF-1 (3,3\%). Toutefois, dans les deux bases de données, la mixtion de propofol et de fentanyl n'a pas été associée à un risque accru d'événement indésirable comparativement au propofol seul.

Conclusion: II existe des différences importantes entre les SU, au Canada, quant aux choix des médicaments utilisés pour les sédations interventionnelles en vue des cardioversions

From the *Department of Emergency Medicine, McMaster University, Hamilton, ON; †Department of Emergency Medicine, University of Ottawa, Ottawa, ON; ¥Ottawa Hospital Research Institute, Ottawa, ON; §Division of Emergency Medicine, University of Calgary, Calgary, AB; $\llbracket$ Department of Emergency Medicine, Queen's University, Kingston, ON; **Department of Emergency Medicine and School of Public Health, University of Alberta, Edmonton, AB; ††Division of Emergency Medicine, University of Toronto, Toronto, ON; ¥¥Department of Emergency Medicine, Dalhousie University, Halifax, NS; §§Department of Emergency Medicine, University of British Columbia, Vancouver, BC; and the TाUniversity of Ottawa Heart Institute, University of Ottawa, Ottawa, ON.

Correspondence to: Dr. David Clinkard, McMaster University, Department of Emergency Medicine, Hamilton General Hospital, Hamilton, ON; Email: dclinkard@qmed.ca 
électriques, et l'emploi du propofol seul comme agent de sédation a gagné du terrain au fil du temps. Le risque d'événement indésirable découlant de la sédation interventionnelle durant la cardioversion est faible, mais non insignifiant. D'après les résultats de l'étude, I'adjonction de fentanyl au propofol, comme analgésique, n'est pas associée à un risque accru d'événement indésirable.

Keywords: cardioversion, sedation, adverse events, propofol, fentanyl

\section{INTRODUCTION}

Atrial fibrillation (AF) is the most common cardiac dysrhythmia treated in the emergency department (ED). ${ }^{1}$ In Canada, symptomatic episodes of paroxysmal AF are increasingly managed entirely in the $\mathrm{ED}$, without subsequent admission to hospital. ${ }^{1-3} \mathrm{ED}$ management of symptomatic $\mathrm{AF}$ is focused on ventricular rate control or restoration of sinus rhythm, followed by primary or secondary prevention of thromboembolism. ${ }^{1}$ Management is guided by multiple considerations, including patient stability, age, comorbidities, and specific characteristics of the patient's presentation such as AF duration and associated complications (e.g., cardiac ischemia, heart failure, transient ischemic attack/stroke). In low risk patients, restoration of sinus rhythm via electrical or pharmacologic cardioversion is recommended for symptomatic $\mathrm{AF}$ of duration less than 48 hours, although no approach has been conclusively proven superior, and wide variations exist among practice sites. ${ }^{2,5}$

Electrical cardioversion is a short, painful procedure that is usually performed under procedural sedation. Multiple medications have been shown to be safe and effective for sedation in the ED, with propofol, ketamine, midazolam, fentanyl, and etomidate being commonly used alone or in combination. ${ }^{6,7}$ Many studies have evaluated medication combinations for extended procedures, such as fracture reductions or abscess drainage, but few have included electrical cardioversion. Studies evaluating sedation regimens for cardioversion are small and heterogeneous in terms of the sedative agents evaluated. ${ }^{8-12}$ Thus, there is a paucity of evidence to guide sedative medication choice to ensure optimal patient outcomes for electrical cardioversion in symptomatic AF.

The objectives of this study were to first quantify ED practice variation in the selection of sedation medication for electrical cardioversion of $\mathrm{AF}$ and atrial flutter (AFL) in eight major academic hospitals across Canada, and secondarily to investigate the adverse event risk associated with different sedative medication choices for a direct current cardioversion.

\section{METHODS}

\section{Study design and setting}

This is a secondary analysis of two cohort studies describing the ED management of recent onset $\mathrm{AF}$ or AFL. Recent Onset Atrial Fibrillation or Flutter-0 (RAFF-0) was a retrospective health records review of ED patients with AF or AFL, ${ }^{5}$ whereas Recent Onset Atrial Fibrillation or Flutter-1 (RAFF-1) was a prospective cohort study. ${ }^{13}$

Patients were enrolled in RAFF-0 or RAFF- 1 if they were 18 years of age or older with a primary diagnosis of a recent-onset episode (first or recurrent) of symptomatic rapid AF or AFL. Inclusion criteria for both studies included a clear history of onset within 48 hours or onset within 7 days on anticoagulants with an international normalized ratio $>2$. Patients were excluded if $\mathrm{AF}$ or $\mathrm{AFL}$ was permanent or if the $\mathrm{AF}$ diagnosis was secondary to another primary presentation (e.g., alcohol withdrawal). The research ethics boards at all participating hospitals approved this study.

The methods of the RAFF-0 health records review study are described in detail elsewhere. ${ }^{4}$ At each site, a trained health records analyst created a list of encounters using electronic hospital database searches. Potential cases were reviewed by a trained research assistant who determined eligibility and abstracted data on a standardized data extraction form. A central experienced research coordinator reviewed cases for completeness and quality assurance. Data were then entered by a trained data entry specialist. This study included 1,068 patients (Figure 1) presenting to eight Canadian academic centres with a primary diagnosis of recent-onset (first episode or recurrent) of AF or AFL from January 1, 2008 to December 31,2008 . Of these, 428 (40\%) patients underwent electrical cardioversion, and 420 (98\%) had sedation records available and were included in this analysis.

RAFF-1 was a prospective cohort study at six academic hospitals (all of which had participated in the RAFF-0 study) from January 1, 2010 to January 31, 2012. ${ }^{13}$ All patients had a primary diagnosis of symptomatic rapid 


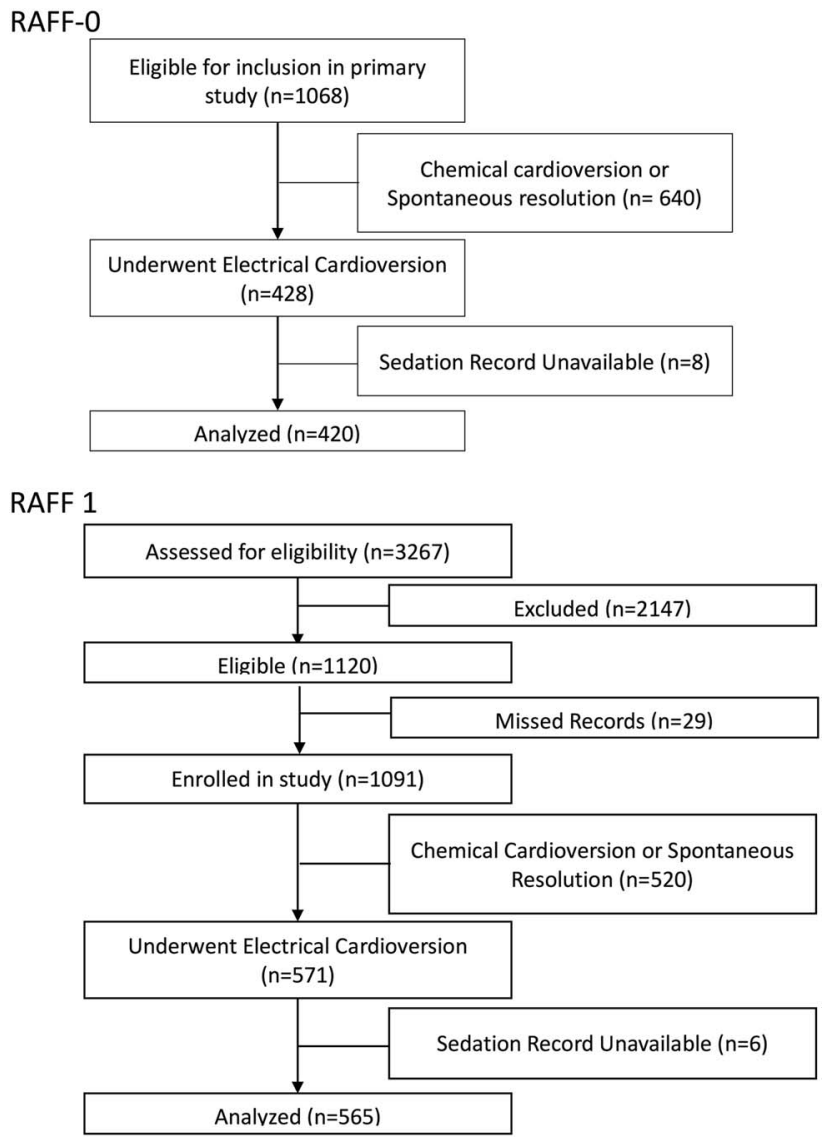

Figure 1. Patient flow diagrams for 1068 patients in RAFF-0 and 3267 patients in RAFF-1.

$\mathrm{AF}$ where symptoms required urgent management and where acute rhythm control was a reasonable option. RAFF-1 subjects were prospectively enrolled when a primary diagnosis of $\mathrm{AF}$ (first episode or recurrent) was made by the attending physician. A trained research assistant prospectively recorded ED management as well as abstracted outcome data from patient records. Of the 3,267 patients screened for the RAFF- 1 study, 1,120 met study inclusion criteria, and of those 1,091 patients were enrolled. Of the enrolled patients, 571 (52\%) patients underwent electrical cardioversion, and 565 (99\%) had sedation records available to be included in this analysis (see Figure 1).

Participating hospitals are academic tertiary care centres in Canada and have an annual ED census between 45,000 and 80,000 patients.

\section{Data analysis}

Baseline subject characteristics as well as within- and among-site variation in sedation medication choices were quantified with descriptive statistics. Where possible, temporal variations within and between sites were examined by comparing the RAFF- 1 and RAFF- 0 data sets. Due to heterogeneity in study design, outcome definition, and ascertainment, data sets were analysed individually and not pooled.

Sedative regimens examined included propofol alone, propofol/fentanyl, propofol/midazolam, propofol/fentanyl/midazolam, and propofol/other. The propofol/ other drug combination comprised propofol/ketamine, propofol/other (specific other drug not recorded), or propofol/fentanyl/other, each of which was used with very small frequency.

Adverse events were abstracted from medical records and included negative sequelae due to sedation. The RAFF-0 study classified adverse events into aspiration, hypoxia (saturation $<90 \%$ ), or "other." Trained nurses using charts and reviewing sedation records classified "other" adverse events to include bradycardia, emesis, apnea, manual airway control, as well as "not defined." The RAFF-1 study defined adverse events as either hypoxia or aspiration.

Unadjusted relative risks for adverse event occurrence were calculated for the four sedative combinations compared to propofol alone. To adjust for potential confounders, we conducted a main-effects multinomial logistic regression analysis with the incidence of adverse events as the outcome. Regression models were constructed using clinically and conceptually relevant covariates and used a backward stepwise variable selection procedure. The final model was included as potential confounders: systolic blood pressure $<120 \mathrm{~mm} \mathrm{Hg}$, use of IV rate control medications prior to sedation, age $>65$, and patient use of oral antihypertensive agents.

For each data set, regression models were fitted to generate an adjusted odds ratio for each drug combination compared to propofol alone. Due to the low number of adverse events in the RAFF-1 data set, bivariable and regression analyses were not able to be performed for the drug combinations of propofol/fentanyl/midazolam and propofol/midazolam.

Data analysis was conducted with SPSS statistical software, version 17.0 (IBM Corp, Armonk, NY).

\section{RESULTS}

Patient enrolment for RAFF-0 and RAFF- 1 is shown in Figure 1. Patient demographics are presented in Table 1. 


\begin{tabular}{|c|c|c|}
\hline & $\begin{array}{l}\text { RAFF-0 } \\
(n=420)\end{array}$ & $\begin{array}{l}\text { RAFF-1 } \\
(n=565)\end{array}$ \\
\hline Male, n (\%) & $279(66.4)$ & $389(68.8)$ \\
\hline Age (SD) & $59(15.2)$ & $60.4(15.3)$ \\
\hline \multicolumn{3}{|l|}{ Initial rhythm, n (\%) } \\
\hline Atrial fibrillation & $368(87.6)$ & $470(82.3)$ \\
\hline Atrial flutter & $52(12.4)$ & $101(17.7)$ \\
\hline Duration of symptoms (hours) (SD) & $11.4(20.0)$ & $7.6(8.8)$ \\
\hline Initial HR (SD) & $123.4(28.1)$ & $119(30.3)$ \\
\hline CHADS2 > 0, n (\%) & $211(50.2)$ & $285(50.4)$ \\
\hline Past atrial fibrillation, n (\%) & $397(73.1)$ & $399(70.6)$ \\
\hline $\begin{array}{l}\text { Prior pharmacologic } \\
\text { cardioversion, } \mathrm{n}(\%)\end{array}$ & $60(14.3)$ & $104(18.4)$ \\
\hline Prior electrical cardioversion, n (\%) & $173(41.2)$ & $277(49.0)$ \\
\hline \multicolumn{3}{|l|}{ Past medical history, n (\%) } \\
\hline Prior stroke & $15(3.6)$ & $32(5.7)$ \\
\hline Hypertensive & 167 (39.8) & 224 (39.6) \\
\hline Diabetic & $28(6.7)$ & $42(7.4)$ \\
\hline Congestive heart failure & $6(1.4)$ & $19(3.4)$ \\
\hline CAD & $56(13.3)$ & $70(12.4)$ \\
\hline Valvular heart & $29(6.9)$ & $47(8.3)$ \\
\hline Pacemaker & $7(1.7)$ & $19(3.4)$ \\
\hline COPD & $32(7.6)$ & $48(8.5)$ \\
\hline \multicolumn{3}{|l|}{ Medications, n (\%) } \\
\hline Warfarin & $105(25.0)$ & $154(27.3)$ \\
\hline$\beta$-blocker & $134(31.9)$ & $221(39.1)$ \\
\hline Calcium channel blocker & $64(15.2)$ & 93 (16.5) \\
\hline Sotalol & $33(7.9)$ & $35(6.2)$ \\
\hline Amiodarone & $19(4.5)$ & $28(5.0)$ \\
\hline Digoxin & $10(2.4)$ & $15(2.7)$ \\
\hline
\end{tabular}

Patients were predominantly male, $66.4 \%$ and $68.8 \%$ (RAFF-0 and RAFF-1), age 59 (RAFF-0) and 60.4 years old (RAFF-1). Presenting rhythm was AF in $87.6 \%$ of RAFF- 0 patients and $82.3 \%$ of RAFF- 1 patients. Initial duration of symptoms was 11.4 hours and 7.6 hours in RAFF- 0 and RAFF-1, respectively. Cardioversion success rates by medication choice are shown in Table A1 (see supplementary material).

In both data sets, the combination of propofol/fentanyl was the most commonly used sedative regimen $(63.8 \%$ and $52.7 \%$ for RAFF- 0 and RAFF-1, respectively), followed by propofol alone (27.9\% and $37.3 \%$ for RAFF-0 and RAFF-1, respectively) (Figure 2, Table 2).

There was substantial variation in sedative choice among EDs. In the 2008 cohort, six of eight sites primarily used propofol in combination with fentanyl, whereas two sites primarily used propofol alone (Figure 3, A). From 2010

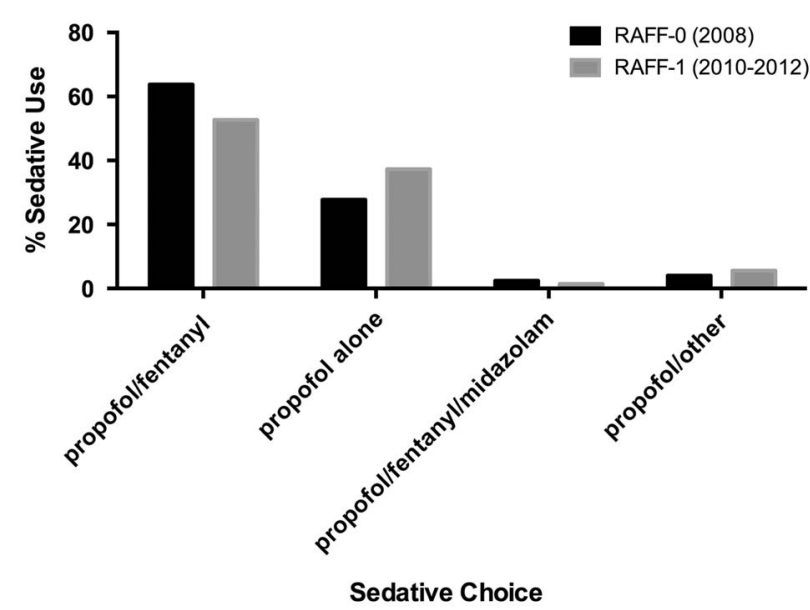

Figure 2. Bar chart showing sedative choice in RAFF-0 and RAFF-1.

to 2012, propofol/fentanyl was used most frequently at five of six hospitals (Figure 3, B).

At sites with data from each temporally separate cohort (Sites 1, 2, 3, 4, and 5), the use of propofol alone increased from $27.7 \%$ in 2008 to $37.4 \%$ in $2010-2012$, whereas the use of the propofol/fentanyl in combination decreased from $62.4 \%$ to $50.5 \%$.

The RAFF-0 data set contained 58 cardioversions with sedation-related adverse events (13.5\%), of which 57 had sedative records available, whereas the RAFF-1 data set contained 19 adverse events (3.3\%). Figure 4 shows the pooled adverse events by sedative type, and Tables A2 and A3 (see supplementary material) show adverse event by sedative type. The majority of adverse events were associated with the combination of propofol/fentanyl/midazolam (22\%). Table A4 shows the unadjusted relative risks of an adverse event for each medication compared to propofol alone in each data set.

Multinomial logistic regressions evaluated the comparative risk of adverse events for the sedative regimens compared to propofol alone, after adjusting for potential confounders. In the RAFF- 0 data set, the use of propofol/fentanyl/midazolam in combination was associated with a higher risk of and adverse events compared to propofol alone. No sedative combination was associated with an increased adjusted risk of adverse events compared to propofol alone in the RAFF-1 data set (Table 3).

\section{DISCUSSION}

This study examines the variation in sedation medication choices for electrical cardioversion in two geographically 


\begin{tabular}{|c|c|c|c|c|}
\hline \multirow[b]{2}{*}{ Drug combination } & \multicolumn{2}{|r|}{ RAFF-0 } & \multicolumn{2}{|r|}{ RAFF-1 } \\
\hline & $\begin{array}{l}\text { Sedative } \\
\text { regimen (\%) } \\
n=420\end{array}$ & $\begin{array}{l}\text { Adverse events involving propofol } \\
\text { or propofol combination (\%) } \\
\qquad n=53\end{array}$ & $\begin{array}{c}\text { Sedative } \\
\text { regimen (\%) } \\
n=565\end{array}$ & $\begin{array}{l}\text { Adverse events involving propofol } \\
\text { or propofol combination (\%) } \\
\qquad n=17\end{array}$ \\
\hline Propofol/fentanyl & $268(63.8)$ & $35(66.0)$ & $298(52.7)$ & $11(64.7)$ \\
\hline Propofol alone & $117(27.8)$ & $10(18.8)$ & 211 (37.3) & 4 (23.5) \\
\hline $\begin{array}{l}\text { Propofol/fentanyl/ } \\
\text { midazolam }\end{array}$ & $10(2.4)$ & $4(7.5)$ & $8(1.4)$ & $0(0)$ \\
\hline Propofol/other & $17(4.0)$ & $4(7.5)$ & $32(5.6)$ & $2(11.7)$ \\
\hline
\end{tabular}
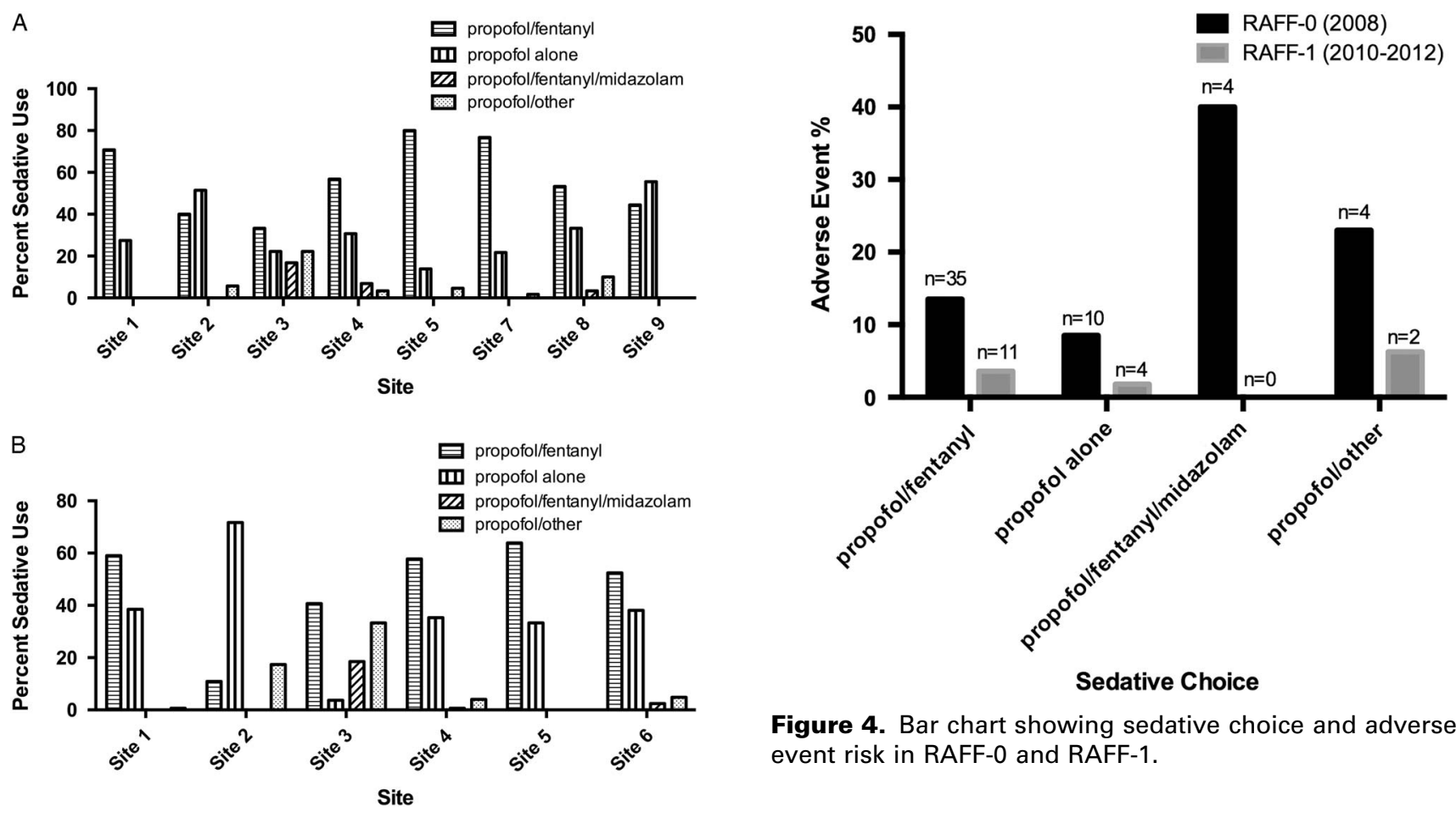

Figure 3. Bar chart showing sedative choices in A) eight academic tertiary care centers in RAFF- 0 and $B$ ) six centers in RAFF-1.

distributed patient cohorts with acute, symptomatic AF. The most commonly used sedative was a combination of propofol/fentanyl, followed by propofol alone. However, substantial variation was observed in sedation medication choices among the different sites, particularly in the use of agents combined with propofol. Although evidence supports the use of propofol and ketamine mixtures for procedural sedation, ${ }^{14-16}$ only two sites used this combination to any appreciable extent. This variation is not surprising given the other variation in RAFF-1 management previously observed between these same hospitals. ${ }^{4}$

Figure 4. Bar chart showing sedative choice and adverse event risk in RAFF-0 and RAFF-1.

Comparing the RAFF-0 and RAFF-1 data sets temporally, the use of propofol/fentanyl declined roughly $10 \%$, with the majority of this decline attributable to increased use of propofol alone as a sedative agent.

Choosing the medications required for any sedation requires physicians to balance effectiveness against potential adverse effects. Guidelines support the safety of multiple agents, including propofol and ketamine, for procedural sedation. ${ }^{17}$ To date, only small studies evaluating the safety and effectiveness of these agents specifically in electrical cardioversion have been conducted. $^{8-12}$ No studies have directly compared propofol and fentanyl or propofol and ketamine against propofol alone for electrical cardioversion. 


\begin{tabular}{|c|c|c|}
\hline Variable & RAFF-0 OR (95\% Cl) & RAFF-1 OR $(95 \% \mathrm{Cl})$ \\
\hline $\begin{array}{l}\text { Propofol/fentanyl/ } \\
\text { midazolam }\end{array}$ & $9.55(2.05-44.45)$ & - \\
\hline Propofol/fentanyl & $1.64(0.77-3.47)$ & $2.056(0.64-6.60)$ \\
\hline Propofol/other & $3.57(0.90-14.11)$ & $3.44(0.58-20.28)$ \\
\hline
\end{tabular}

Propofol and fentanyl both can cause apnea at high doses and can have an additive effect when used together. Practitioners may believe that the risk of an adverse event with the addition of fentanyl to propofol is not worth the potential benefit of increased analgesia, which may explain the increased use of propofol alone as a sedating medication from 2008 to 2012 .

A secondary aim of this analysis was to examine the risk of adverse effects of sedation medication choices for cardioversion. The addition of fentanyl and midazolam to propofol was found to significantly increase the risk of an adverse event in the RAFF-0 data set compared to propofol alone. The drug combination of propofol/ other was also found to significantly increase the risk of an adverse event compared to propofol alone in the RAFF-0 data set. In both data sets, the use of propofol/ fentanyl was not associated with an increased adverse event risk compared to propofol alone, after adjusting for potential confounders. This suggests that the analgesic benefit of adding fentanyl to propofol may be worth the risk of excessive patient sedation.

\section{LIMITATIONS}

A recent review of propofol use in the ED for all procedural sedations showed propofol alone to cause a hypotensive event between $0 \%$ and $17 \%$ of the time. ${ }^{18}$ The adverse event risk in these data sets matches these cited event rates. However, there was a surprising difference in the risk of adverse events between the two data sets analysed here. This is likely due to differences in the definition of adverse events in each cohort study and the method of collection. The adverse events collected in RAFF-1 were collected by nurses prospectively and only included aspiration and hypoxia with no other options. The definition of adverse event in RAFF-0, collected retrospectively from all sections of the patient's chart (sedation record, respiratory therapist notes, physician notes), was much broader, leading to a higher adverse event risk in this data set. Aspiration and hypoxia event rates were similar between data sets. Some clinically important adverse events, such as respiratory depression, ${ }^{19}$ were omitted from both data sets, thus leading to a possible underestimate of the adverse event risk.

Another important limitation stems from the individualized nature of medication choice. Physicians were able to tailor medication choice and dose to the individual patient. Thus, the observed results may be vulnerable to selection and indication bias. However, no significant demographic differences were observed between those who suffered an adverse event compared to those who did not.

\section{CONCLUSION}

The risk of adverse events from procedural sedation for cardioversion in the ED is low but not negligible, and retrospective analysis in the RAFF-0 data set failed to demonstrate increased risk of adverse events with the combination of propofol/fentanyl compared to propofol alone. These data demonstrate substantial differences in medication choice within and among Canadian academic centres. Over time, it appears that multimodal sedation is becoming less popular compared to using propofol alone for cardioversion.

Acknowledgements: Dr. Stiell holds a Distinguished Professorship and University Health Research Chair from the University of Ottawa. Dr. Rowe is supported by a Tier I Canada Research Chair in Evidence-based Emergency Medicine through the Government of Canada (Ottawa, ON). Dr. Perry holds a New Investigator Award from the Canadian Institutes of Health Research and a Clinical Research Chair from the University of Ottawa. We would like to thank the research staff at participating hospitals for their contributions towards patient enrolment and follow-up, as well as data collection. The authors acknowledge the following research personnel at the study hospitals: The Ottawa Hospital, Ottawa, Ontario (Pam Sheehan, RN; Pam Ladoucer, RN; Julie Finnigan, RN; Connor Sheehan, BAH; Ellias Horner, BAH; and Linda Brown, RN); Kingston General Hospital, Kingston, Ontario (Kathy Bowes, RN; Karen Lollar, RN; Jane Reid, RN; Nicholas Martin, MD; Gauri Ghate, MD; Carla Graham, RN; and Catherine Bobek, MD); Mount Sinai Hospital, Toronto, Ontario (Michelle Loftus, RN; Genevieve Banshard, RN; and Jackie Ripco, RN); Jewish General Hospital, Montreal, Quebec (Antoinette Colacone, RN; Chris Tselios, BSc; and Paulina Gasioworska, MD); University of Alberta Hospital, Edmonton, Alberta (Debbie Boyko, RN; Jennifer Moore, RN; Mira Singh, MA; Gemma Percival, RN; and 
Jennifer Goede, RN); Foothills Medical Centre, Calgary, Alberta (Renee Vilneff, RN; Karen Melon, RN; Allan Kostyniuk, BA; Hachem Nasri, MD; Fareen Zaver, MD; Rebecca Machacek, RN candidate; Stevie Anderson, RN candidate; and Carly More, RN candidate); St. Paul's Hospital, Vancouver, British Columbia (Mahi Etminan, RN; Iraj Poureslami, PhD; Arash Eftekhari, MD; and Maziar Sighary, BSc); Queen Elizabeth II HSC, Halifax, Nova Scotia (Agnieszka Grabowski-Comeau, RN). The authors also acknowledge staff of the hospital health records departments, our colleagues at the Ottawa Hospital Research Institute, and the staff responsible for coordinating these studies (Maureen Lowe, My-Linh Tran, Angela Marcantonio, Sheryl Domingo, Connor Sheehan, BA; and Jennifer Brinkhurst, BA) for their assistance with this project, and Dr. Eddy Lang for his insightful suggestions for the article. Finally, we would like to thank the emergency department physicians and nurses at all participating sites for assisting research teams with identifying potential patients and data collection.

Competing interests: None declared.

\section{SUPPLEMENTARY MATERIAL}

To view supplementary material for this article, please visit https://doi.org/10.1017/cem.2017.20

\section{REFERENCES}

1. Stiell IG, Macle L. Canadian Cardiovascular Society atrial fibrillation guidelines 2010: management of recent-onset atrial fibrillation and flutter in the emergency department. Can 7 Cardiol 2011;27(1):38-46.

2. Verma A, Cairns JA, Mitchell L, et al. 2014. Focused update of the Canadian cardiovascular guidelines for the management of atrial fibrillation. Can 7 Cardiol 2014;30(12):1114-30.

3. Camm AJ, Kirchhof P, Lip GY, et al. Guidelines for the management of atrial fibrillation: The Task Force for the Management of Atrial Fibrillation of the European Society of Cardiology (ESC). Eur Heart 7 2010;31(19):2369-429.

4. Atzema CL, Austin PC, Miller E, et al. A population-based description of atrial fibrillation in the emergency department, 2002 to 2010. Ann Emerg Med 2013;62(6):570-7.e7.

5. Stiell IG, Clement CM, Brison RJ, et al. Variation in management of recent-onset atrial fibrillation and flutter among academic hospital emergency departments. Ann Emerg Med 2011;57(1):13-21.
6. Innes G, Murphy M, Nijssen-Jordan C, et al. Procedural sedation and analgesia in the emergency department. Canadian consensus guidelines. 7 Emerg Med 1999;17(2):145-56.

7. Campbell SG, Magee KD, Kovacs GJ, et al. Procedural sedation and analgesia in a Canadian adult tertiary care emergency department: a case series. CFEM 2006;8(2):85-93.

8. Kalogridaki M, Souvatzis X, Mavrakis HE, et al. Anaesthesia for cardioversion: a prospective randomized comparison of propofol and etomidate combined with fentanyl. Hell 7 Cardiol 2011;52:483-8.

9. Wood J, Ferguson C. Best evidence topic report. Procedural sedation for cardioversion. Emerg Med 7 2006;23(12):932-4.

10. Parlak M, Parlak I, Erdur B, et al. Age effect on efficacy and side effects of two sedation and analgesia protocols on patients going through cardioversion: a randomized clinical trial. Acad Emerg Med 2006;13(5):493-9.

11. Bellone A, Etteri M, Vettorello M, et al. Cardioversion of acute atrial fibrillation in the emergency department: a prospective randomised trial. Emerg Med 7 2012;29(3):188-91.

12. Coll-Vinent B, Sala X, Fernández C, et al. Sedation for cardioversion in the emergency department: analysis of effectiveness in four protocols. Ann Emerg Med 2003;42(6):767-72.

13. Stiell IG, Borgundvaag B, Clement CM, et al. Correlates of 30-day adverse events for ED patients with recent-onset atrial fibrillation and flutter (RAFF). CFEM 2013;15(S1):S11.

14. Andolfatto G, Abu-Laban RB, Zed PJ, et al. Ketaminepropofol combination (ketofol) versus propofol alone for emergency department procedural sedation and analgesia: a randomized double-blind trial. Ann Emerg Med 2012;59(6): 504-12.e2.

15. Arora S. Combining ketamine and propofol ("ketofol") for emergency department procedural sedation and analgesia: a review. West 7 Emerg Med 2008;9(1):20-3.

16. Messenger DW, Murray HE, Dungey PE, et al. Subdissociative-dose ketamine versus fentanyl for analgesia during propofol procedural sedation: a randomized clinical trial. Acad Emerg Med 2008;15(10):877-86.

17. Godwin SA, Burton JH, Gerardo CJ, et al. Clinical policy: procedural sedation and analgesia in the emergency department. Ann Emerg Med 2014;63(2):247-58.

18. Black E, Campbell S, Zed P. Propofol for procedural sedation in the emergency department: a qualitative systematic review. Ann Pharmacother 2013;47(6):856-68.

19. Bhatt M, Kennedy RM, Osmond MH, et al. Consensusbased recommendations for standardizing terminology and reporting adverse events for emergency department procedural sedation and analgesia in children. Ann Emerg Med 2009;53(4):426-35.e4. 